\title{
Galpão Bela Maré: sentidos e práticas curatoriais urgentes
}

\author{
Galpão Bela Maré: \\ Senses and Urgent Curatorial Practices
}

\section{Galpão Bela Maré: sentidos y prácticas curatoriales urgentes}

Isabela Souza da Silva (Observatório das Favelas, Rio de Janeiro, Brasil) * Jean Carlos de Souza dos Santos (Galpão Bela Maré, Rio de Janeiro, Brasil) **

https://doi.org/10.22409/poiesis.v21i35.40411

RESUMO: O presente artigo apresenta o Galpão Bela Maré, um projeto da organização da sociedade civil de interesse público Observatório de Favelas do Rio de Janeiro em parceria com a Automatica Produtora que, desde 2011, vem construindo na Nova Holanda, uma das favelas do Conjunto de Favelas da Maré, localizada na zona norte do Rio de Janeiro, um conjunto de práticas curatoriais e de produção cultural que assinalam a favela como lugar possível para a arte contemporânea habitar e, ainda, através das linguagens artísticas, criar metodologias de visibilização de sujeitos/as, territórios e questões periféricas. Esta aposta política está centrada em pressupostos que respondem às formas dominantes a partir das quais territórios, corpos/as e questões periféricas são narrados/as e, ainda, indicam para um alargamento de protagonismos no que concerne às práticas artísticas em sua amplitude.

PALAVRAS-CHAVE: Galpão Bela Maré; curadoria; descolonização e artes

\footnotetext{
* Isabela Souza é doutoranda em Geografia na Universidade Federal Fluminense (UFF). Atualmente é diretora da OSCIP Observatório de Favelas do Rio de Janeiro. E-mail: isabela@observatoriodefavelas.org.br

** Educador, artista visual e curador independente. Mestre em Arte e Cultura Contemporânea pelo PPGARTES/UERJ. É o coordenador da Área de Educação do Galpão Bela Maré. E-mail: jean@observatoriodefavelas.org.br
} 
ABSTRACT: This article presents the Galpão Bela Maré, a project of the civil society organization of public interest Observatório de Favelas do Rio de Janeiro in partnership with Automatica Produtora, which since 2011 has been building in Nova Holanda, one of the favelas of the Conjunto de Favelas da Maré. located in the north of Rio de Janeiro, a set of curatorial and cultural production practices that mark the favela as a possible place for contemporary art to inhabit and, also, through artistic languages to create methodologies for the visibility of subjects, territories and peripheral issues. This political bet is centered on assumptions that respond to the dominant forms from which territories, bodies and peripheral issues are narrated and also indicate a broadening of protagonism regarding artistic practices in their breadth.

KEYWORDS: Galpão Bela Maré; curatorship; decolonization and arts

RESUMEN: Este artículo presenta el Galpão Bela Maré, un proyecto de la organización de la sociedad civil de interés público del Observatorio de Favela de Río de Janeiro en colaboración con Automatica Produtora, que desde 2011 ha estado construyendo en Nova Holanda, una de las favelas del Conjunto de Favelas da Maré, ubicado en el norte de Río de Janeiro, un conjunto de prácticas de producción curatorial y cultural que marcan la favela como un posible lugar para que el arte contemporáneo habite $y$, también, a través de lenguajes artísticos para crear metodologías para la visibilidad de temas, territorios y Problemas periféricos. Esta apuesta política se centra en suposiciones que responden a las formas dominantes a partir de las cuales se narran territorios, cuerpos y asuntos periféricos y también indican una ampliación de protagonismos con respecto a las prácticas artísticas en su amplitud.

PALABRAS CLAVE: Galpão Bela Maré; curadoria; descolonización y artes

Citação recomendada:

SILVA, Isabela Souza da; SANTOS, Jean Carlos de Souza dos. Galpão Bela Maré: sentidos e práticas curatoriais urgentes. Poiésis, Niterói, v. 21, n. 35, p. 71-86, jan./jun. 2020. [https://doi.org/10.22409/poiesis.v21i35.40411] 


\section{Galpão Bela Maré: sentidos e práticas curatoriais urgentes}

Bela Maré: uma heterotopia no campo das artes a partir de outras centralidades

Inaugurado em 2011, o Galpão Bela Maré, localizado em Nova Holanda, uma das 16 favelas que compõem o Conjunto de Favelas da Maré ${ }^{1}$, representa o investimento institucional do Observatório de Favelas do Rio de Janeiro², em parceria com a produtora Automatica $^{3}$, na construção de um espaço alternativo dentro do cenário das artes do Rio de Janeiro metropolitano.
O espaço foi inaugurado com o objetivo de contribuir para a democratização e difusão de todos os tipos de expressões artísticas e seu amplo funcionamento comprova como é possível descentralizar tanto os equipamentos culturais quanto as possibilidades de fruição estética na cidade e, com efeito, reconhecer os/as moradores/as dos territórios populares como cidadãos/ãs com plenos/as direitos, afastando-os/as dos juízos de valor hegemônicos, que estigmatizam, criminalizam e muitas vezes são omissos a sujeitos/as e territórios fora dos eixos centrais. 
No caso do Rio de Janeiro, a partir da representação maior da hierarquia social baseada no acesso a bens distintivos, um conjunto de elementos se fundiu para construir as formas hegemônicas de representação das favelas e seus moradores: a sua associação com a pobreza econômica; a falta de formação escolar; a predominância do trabalho manual; o fenótipo dos moradores - em sua grande maioria pretos ou pardos; a precariedade das moradias; dos serviços e equipamentos urbanos; a origem nordestina, região considerada "problema" no país; a ocupação ilegal de terras; a falta de pagamento de taxas e impostos diversos etc.

Construíram-se, então, perfis específicos do morador das favelas e de seu território que passaram a ser generalizados no juízo comum; nas definições legais e formais e mesmo no plano acadêmico. № processo, as favelas e seus moradores passaram a ser percebidos de forma homogênea, apesar de sua rica diversidade (tipo de sitio; densidade populacional; acesso a serviços e equipamentos; perfil populacional; grau de organização comunitária etc.) como espaços desprovidos de condições básicas de cidadania, na verdade, espaç̧os de sub-cidadãos. (SILVA, 2010, p. 4)

No Bela trabalhamos a partir da perspectiva primeira de que o campo artístico e todas as suas camadas e possibilidades de produção, difusão, formação e mobilização são instrumentos de desenvolvimento político, econômico, social e territorial, confirmando o papel da arte como central na ampliação das possibilidades existenciais de múltiplos grupos sociais.

\section{A afirmação artística e estética positiva dos territó- rios populares, ao nosso ver, caminha em conso- nância com a ampliação dos significados mais de- mocráticos sobre a cidade e seus sujeitos e multi- plicam as formas de comunicação destes sentidos. (SILVA, 2019, p. 151)}

Assim, há uma aposta política por, a partir deste território das artes, propor e visibilizar agendas de superação de desigualdades e de radicalização da democracia. Na Maré, a partir de uma periferia, entre 2011 e janeiro de 2020 realizamos cerca de 20 exposições/mostras e recebemos mais de $50 \mathrm{mil}$ visitantes, sendo quase $10 \mathrm{mil}$ apenas no ano de 2019.

Se a favela, como termo genérico carregado de significados, é hegemonicamente lida como território do "medo", da "violência", da "precariedade", da "ausência" e "desprovido de condições básicas", como apontou o

Isabela Souza da Silva; Jean Carlos de Souza dos Santos, Galpão Bela Maré: sentidos e práticas curatoriais... 
geógrafo Jailson Silva no trecho acima, a escolha da Maré como sede do Galpão é uma fissura nestas leituras e representa múltiplas possibilidades de construção de outras referências para todas as periferias do Brasil e do mundo, marcando esses territórios como lugares possíveis para a arte habitar.

Entre 2011 e 2017, foram realizadas cinco edições da exposição Travessias. Somadas, as mostras reuniram mais de 50 artistas de todo o Brasil e colocaram a Maré e seus/ suas moradores/as no mapa das artes visuais brasileiras e de nossas práticas culturais, recentrando o lugar da arte na cidade e criando fluxos contínuos de pessoas de todas as partes do Rio de Janeiro metropolitano rumo a Nova Holanda.

Ter trabalhos de Marcos Chaves, Raul Mourão, Carlos Vergara, Vik Muniz, Ernesto Neto, Luiz Zerbini, Dora Longo Bahia, Regina Silveira, Jota Mombaça, Bárbara Wagner, entre outros/as, é um movimento que transforma os motivos pelos quais a cidade se desloca, física e simbolicamente. É um fluxo que recupera e educa sobre a dimensão do direito à fruição artística, do direito ao uso comum de um equipamento cultural público - não no sentido estatal, mas sim, de patrimônio de uso coletivo.

Em 2014, o Galpão Bela Maré passou a fazer parte da Rede Carioca de Pontos de Cultura e, a partir de então, passaram a ser realizadas também no espaço ações que preveem, principalmente, a articulação de coletivos e artistas mareenses, e também da cidade do Rio de Janeiro, intervenções culturais externas em torno do espaço físico do Galpão, atividades formativas para públicos de diversas faixas etárias, seminários, exibições de filmes, festivais, rodas de bate-papos, debates etc.

Em 2017, além da quinta edição da Travessias, o Bela Maré recebeu, através de uma parceria com o Itaú Cultural, a exposição Diálogos Ausentes que, com curadoria de Diane Lima e Rosana Paulino, apresentou produções contemporâneas de 17 artistas e grupos de negras e negros de todo o Brasil.

A produção dos(as) artistas presentes nesta mostra também nos fala muito de um Brasil que não quer reconhecer a si mesmo diante do espelho da sua realidade populacional e por isso despreza, cotidianamente, talvez aquilo que provavelmente tenha de melhor para oferecer ao mundo, contentando- 
se em ser uma cópia mirrada do Norte. (PAULINO, 2016, p. 3)

A partir de então, o Galpão está aberto regularmente de terça a sábado e recebeu outras tantas exposições e mostras. De 2017 em diante, além da urgência por marcar a favela como espaço possível para a arte contemporânea e, assim, mobilizar travessias até então pouco óbvias, o trabaIho passou a construir processos cada vez mais consistentes por meio da arte, a protagonizar modos de fazer periféricos e seus/suas agentes, e para efetivar isso, as curadorias foram, com certeza, uma das grandes chaves para o desenvolvimento desta parte complementar ao trabalho que vinha sendo construído até então.

\section{Uma vez que práticas científicas de saber no campo das artes legitimam padrões de beleza, quem me- rece e não merece ser visto, assim como noções de verdadeiro e falso, é importante entender e questi- onar quais corpos e geografias a história da arte ocidental contempla e a quais ela impõe limites e categorias. (LIMA, 2018, p. 246)}

Propostas expositivas mobilizadas por Jean Carlos Azuos (Corpos in Trânsito, Exposição Domingos de Sol, Mostra Superfícies), Ale- xandre Silva (Exposição Domingos de Sol), Ronald Duarte (Exposição Metrópole Transcultural) e Francisco Valdean (Mostra entre a Maré e Alemão); processos de chamamentos públicos na forma de editais (Bela Verão e Bela Verão Transcendências); e a realização da primeira turma da Escola Livre de Artes (Elã ${ }^{4}$ ) foram contemplando e fortalecendo cada vez mais um cena de artistas territorializados/as em espaços periféricos e marcando o Bela Maré como território de encontro, troca, proposição, visibilidade e diálogo sobre estas outras narrativas, outros corpos e outras estéticas das artes. Complementares às ações expositivas, o Bela Maré rompeu seus muros e consolidou uma agenda propositiva de ações educativas, festas e intervenções públicas e buscou fortalecer suas redes sociais e fazer uma comunicação mais ativa com o público da rede. Desta forma, acreditamos que há, a partir das práticas ali constituídas, um processo de expansão, de limites, categorias e narrativas a partir de processos curatoriais e de produção cultural atentas às dimensões de raça, sexualidade, gênero, etárias e territoriais.

A jovem equipe de cerca de dez pessoas, todas oriundas ou residentes em periferias

Isabela Souza da Silva; Jean Carlos de Souza dos Santos, Galpão Bela Maré: sentidos e práticas curatoriais... 
do Rio de Janeiro, que trabalha continuamente no espaço é parte central da alquimia que mobiliza o espaço e sua programação e consideramos que esta é outra chave que nos leva a novos caminhos e formas de construir, a partir da arte, experiências de democratização de saberes, vivências e estéticas. Neste sentido, afirmamos que o Bela concretiza em muitas pequenas delicadezas $^{5}$ os sonhos e apostas de uma instituição que há 18 anos vive a inquietação de buscar consolidar políticas mais generosas para a diversidade de nossa urbe, mas também, e centralmente, de pessoas engajadas para no cotidiano oferecer à metrópole e seus/ suas sujeitos/as um espaço que possibilite práticas outras, talvez mais amorosas para outros/as protagonistas, corpos/as e artistas dissonantes.

\section{De onde vêm e para onde apontam nossas práticas curatoriais recentes}

"Quem cura, cura o quê? Como são delegadas as vozes, como são geridas as relações de poder e quais os critérios institucionais investidos nessa função?" (LIMA, 2016, p. 1)
Tratando-se de Brasil, de nossa história violenta, dos pressupostos desiguais a partir dos quais nossas cidades são organizadas, de nosso atual momento político e do aprofundamento dos desmontes de tantas das nossas instituições democráticas, olhar para dimensões políticas dissonantes de processos curatoriais que tensionam as formas como as relações de poder e os critérios institucionais hegemônicos são instituídos nos parece uma chance de nos agarrarmos em uma possibilidade de nos sentirmos vivos/as! Um caminho de atuar concretamente na busca por reconstruir referências coletivas, pautadas por outras centralidades de corpos, memórias, estéticas, territórios. 
Se fomos forjados em um sistema violento, que nossas práticas respondam à altura: apontando fissuras; abrindo espaços de diálogos; criando fluxos e pontes, chances de nos olharmos nus/nuas e por outros ângulos; desafiando o poder de quem/quens historicamente esteve no poder de definir, de curar. E, assim, forjando outros sentidos, mais honestos e diversos, que disputam com as hierarquias do projeto moderno coIonial de saber, de poder e ser.

A partir desse entendimento, a produção da cultura e da arte está fundamentada em um conjunto de saberes atravessados por relações de poder e seus regimes de visibilidade e verdade. Assim, a prática em perspectiva traz como desafio combater a desvalorização, a negação e o ocultamento das contribuições de outros saberes e epistemologias ao mesmo tempo em que fomenta a produção de conhecimento artístico e cultural fundamentais para assegurar a dignidade humana. Dessa forma, tenta garantir a visibilidade, 0 direito à diferença e a liberdade de expressão e experimentação de artistas, pensadoras/es, ativistas, educadoras/es e curadoras/es que também trabalham em perspectiva interseccionando questões políticas contemporâneas urgentes como as pautas de gênero, classe, raça, entre outras; propõe, por fim, o combate ao racismo estrutural nas instituições de arte e cultura que notadamente criam sistemas de controle e restringem as oportunidades, precarizando as relações de trabalho aos corpos racializados e/ou dissidentes. (LIMA, 2018, p. 247)

Descolonizar o conhecimento na arte, em seus processos e modalidades, é contestar suas estruturas, sentido de valor e legitimação, nas noções estético-poéticas que, baseadas em formatos hegemônicos eurocentralizados, definia as noções de belo e, por consequência, estabelece legitimidades, enquanto modo de fazer artístico e suas ressonâncias em termos de visibilidade.

Um fato que me chama a atenção é a ausência quase total de uma crítica robusta ao nosso hábito de nos pautarmos, talvez na maioria dos casos, em um pensar hegemônico que orienta a realização e a legitimação dos saberes no campo das artes visuais, ou seja, a quase inexistente necessidade de considerarmos a possibilidade da produção de conhecimentos que não sejam apenas reflexos de uma cultura hegemônica, branca e europeia. Isso inclui, obviamente, acolher as produções que estão "à margem" de uma suposta "universalidade" e que independam dessa matriz. (PAULINO, 2016, p. 1)

Isabela Souza da Silva; Jean Carlos de Souza dos Santos, Galpão Bela Maré: sentidos e práticas curatoriais... 
Em nossos exercícios recentes de curadorias expositivas e de programação no Galpão Bela Maré, estamos nos propondo, então, a buscar práticas latinoamefricanas (GONZALEZ, 1988) de curadoria a partir das experiências que construímos no Galpão Bela Maré, centralmente a partir do ano 2017, como movimento de resiliência e criação diante da ordem do inconsciente em um país "cujas formações do inconsciente são exclusivamente europeias, brancas" (GONZALEZ, 1988 , p. 69), que reconhece outras múltiplas presenças em nossa construção cultural e em nossa produção artística.

\section{Essa possível inclusão traz em seu bojo a possibili-} dade de desafiar o que já está estabelecido, rever paradigmas que não se encaixam em nossa realidade e propor novas atitudes e conceitos diante daquilo que não nos representa mais (ou que talvez nunca nos tenha representado). Podemos dizer que, se por um lado novas posturas estão sendo tomadas, a passos lentos, em locais onde elas já deveriam ser um hábito - como nas universidades -, por outro lado alguns artistas, e instituições, tomaram para si parte dessa tarefa. (PAULINO, 2016, p.1)
Nos intermeios que compõem o campo artístico, a curadoria exerce um papel central de poder, na perspectiva e compreensão dos agentes que ela envolve dentro das possibilidades de diálogos e construções. A dimensão principal é que o gesto curatorial, para além de um caráter profissional e também como prática poética, exerce. sobretudo, uma ação política que pode viabilizar deslocamentos conceituais estruturantes.

Neste sentido, a curadoria na qual nos dedicamos e acreditamos mobiliza distintas narrativas, mitologias individuais, percursos e repertórios para constituir uma totalidade. Não está a serviço de um vislumbre plástico, mas, antes, de uma universalidade nas possibilidades de inventar expressões e novas linguagens, em paralelo, aos diálogos institucionais, com o território, o outro e suas recepções e, neste sentido, uma importante ferramenta em processos de desafiar e contestar superioridades. Em síntese, partimos do pressuposto apresentado por Diane Lima: "O principal desafio de instaurar uma prática curatorial em perspectiva passa pela compreensão de que o que estamos fazendo é política". (LIMA, 2018, p. 246) 
Provocar uma reflexão sobre o que venho chamando de "uma prática curatorial em perspectiva decoIonial", aquela que leva em consideração outras perspectivas de conhecimento, performando seu discurso no campo estético, mas também instaurando uma ética nas estruturas institucionais.

(LIMA, 2018, p. 246)

A partir destas constatações, seguimos navegando por rotas e transviamentos de um trabalho, centralmente lideradas por curadorias, que se propõem a borrar as fronteiras que cerceiam as hibridações e invisibilizam sujeitos/as e suas subjetividades,

tências nos circuitos artísticos utópicos que ainda regem a contemporaneidade.

\section{Elementos pouco vivenciados ou discutidos na pro- dução visual da atualidade, como os afetos, as questões ligadas à descolonização dos saberes e 0 racismo enfrentado pelas populações negras e in- dígenas - traço, infelizmente, ainda muito presen- te na sociedade brasileira. (PAULINO, 2016, p. 4)}

A estratégia essencial é a PRESENÇA, de forma que possamos, a partir do que denominamos de "políticas da arte", assumir nossa responsabilidade enquanto instituição em descentramento, e assim mobilizar con-

vocatórias nas quais os corpos urgentes, racializados e interditos possam usufruir de um espaço artístico em sua plenitude, com todas as ferramentas que este possa oferecer por meios estratégicos de suporte e visibilidade.

\section{[...] são microssistemas que vazam, fissuram, reor- ganizam, africana e agrafamente, 0 tecido cultural e simbólico brasileiro, mantendo ativas as possibi- lidades de outras formas de veridicção e percepção do real que dialogam, nem sempre amistosamen- te, com as formas e modelos de pensamento privi- legiados pelo Ocidente. (MARTINS, 1997, p. 35)}

Anunciar, a partir de exposições e programações, novas configurações narrativovisuais no processo de construção de outras cenas, junto aos desejos e riscos que as armadilhas da arte contemporânea propõe, nos parece uma aposta política no sentido de articulações e ações estéticas efetivas possíveis, pautadas por uma diversidade de sujeitos/as e territórios historicamente invisibilizados/as, os/as quais a maior parte dos espaços institucionais, sejam eles da arte ou não, ignoram, rejeitam e/ou reservam um lugar menor ${ }^{6}$.

Isabela Souza da Silva; Jean Carlos de Souza dos Santos, Galpão Bela Maré: sentidos e práticas curatoriais... 
Ao promover uma multiplicidade de vozes, o que se quer, acima de tudo, é quebrar com o discurso autorizado e único, que se pretende universal. Busca-se aqui, sobretudo, lutar para romper com o regime de autorização discursiva. (RIBEIRO, 2017, p. 2017)

Assim, instituímos na prática o desafio de repensar papéis e seus agentes, na crença por uma arte (e uma cidade) mais negra e não branca, feminina e plural em corpos e linguagens, e todas aberturas por estes suscitadas.

É neste sentido que a tarefa do curador não é dissociada de uma atitude crítica. E para que se faça crítica, a pesquisa se impõe como primeira condição de um processo de aquisição e destruição de saberes e verdades. (LAGNADO, 2008 p. 14)

Deste modo, a crítica que as novas curadorias aqui em perspectiva tenciona são os formatos e matrizes acolhidos por vias viscerais as insurgências dos corpos, interseccionalidades frente às armadilhas e desvios da arte contemporânea, no processo de desvelamento de histórias, memórias, no enfrentamento à violência da exclusão e do esquecimento, ao mesmo tempo em que nos dias atuais emergem as novas e urgentes narrativas.

Outras táticas de descolonização da arte, estética e seus desdobramentos no campo da curadoria carregam outras características para as visualidades das exposições, e vêm rompendo a ideia de uma arte ocidentalizada, atribuindo em suas construções uma arte territorializada a partir de diversas cartografias possíveis, consolidando espaços e caminhos fundamentais para uma cena contemporânea mais contaminada e provocada por intercâmbios estéticos e trânsito entre repertórios.

Devemos tomar a inquestionável supremacia branca ocidental no mundo como um sistema político não-nomeado, porque ela estrutura "uma sociedade organizada racialmente, um Estado racial e um sistema jurídico racial, onde o status de brancos e não brancos é claramente demarcado, quer pela lei, quer pelo costume". Um tipo de sociedade em que 0 caráter estrutural do racismo impede a realização dos fundamentos da democracia, quais sejam a liberdade, a igualdade e a fraternidade, posto que semelhante sociedade consagra hegemonias e subalternização racialmente recortadas. (CARNEIR0, 2005, p. 100 apud MILLS, 1997, p. 18) 
As exposições se revelam assim como grandes expoentes que convocam ao espaço, uma dinâmica de poder e redistribuição do mesmo a partir dos/as sujeitos/as. O desafio, no entanto, está na ativação de partilhadas e concepções que, em contestação, não espelhe e reproduza as estruturas coloniais. E, claro, indicamos, a partir de metodologias, estratégias que não fortaleçam diferenciação e/ou distinção entre estéticas, artes e práticas descoloniais da arte, mas que criem mecanismos inaugurais de legitimação e de reconhecimento pleno das heterogeneidades culturais e artísticas, rarquização e fronteirização, reconfigurados a partir da democracia e do sensível das geopolíticas em torno da arte e de seus /suas agentes.

Não se trata mais da arte pela arte, e sim as questões políticas que ela pulsa a partir das estéticas que se instauram no presente, desencadeando novos sentidos e colapsos. Não há espaço para se pensar em uma arte a partir de nichos, estamos lidando com terrenos em falso e suas ciladas. A curadoria, no entanto, se engendra como um caminho possível para elucidação destes indí-

cios e para a reparação da arte e seus dilemas.

Em nossa experiência prática, destacamos, em tom de possível conclusão /encaminhamento, o quanto o processo curatorial - de exposições e mostras e de programações em geral, entre cinemas, atividades formativas etc. - decolonial/dissidente/multiplicadora de protagonismos, que aponta para "literaturas menores"7 (DELEUZE; GUATTARI, 1977), de resiliência e invenção, está intrinsecamente conectado com um trabaIho educativo, que reflete os usos de obras de artes produzidas por artistas negros/as, mulheres, trans, periféricos/as, como ferramentas "de discussão dos problemas enfrentados por essa população e os meios encontrados para a superação desses obstáculos" (PAULINO, 2016, p. 8), em um constante esforço de alongar os sentidos das imagens e narrativas dominantes.

Considerando-se que o olhar que lançamos às pessoas e aos objetos os imbui de características as mais diversas, boas ou más. Estereótipos são criados ou reforçados quando somos diariamente bombardeados por imagens que corporificam preconceitos e lugares instituídos. Repensar esses lu- 
gares implica repensar as imagens que fundaram

simbolicamente o país, e isso não é tarefa peque-

na. Entretanto, artistas das mais diversas áreas

vêm realizando essa tarefa. (PAULINO, 2016, p. 8)

\begin{abstract}
A partir de onde olhamos, consideramos que nossas práticas curatoriais e educativas contribuem efetivamente com esta tarefa de repensar, reimaginar, renarrar a(s) cidade(s), seus/sujeitos/as e seus conceitos, apontando para pluralidades que nos identificam com a diversidade de que somos de fato compostos/as.
\end{abstract}




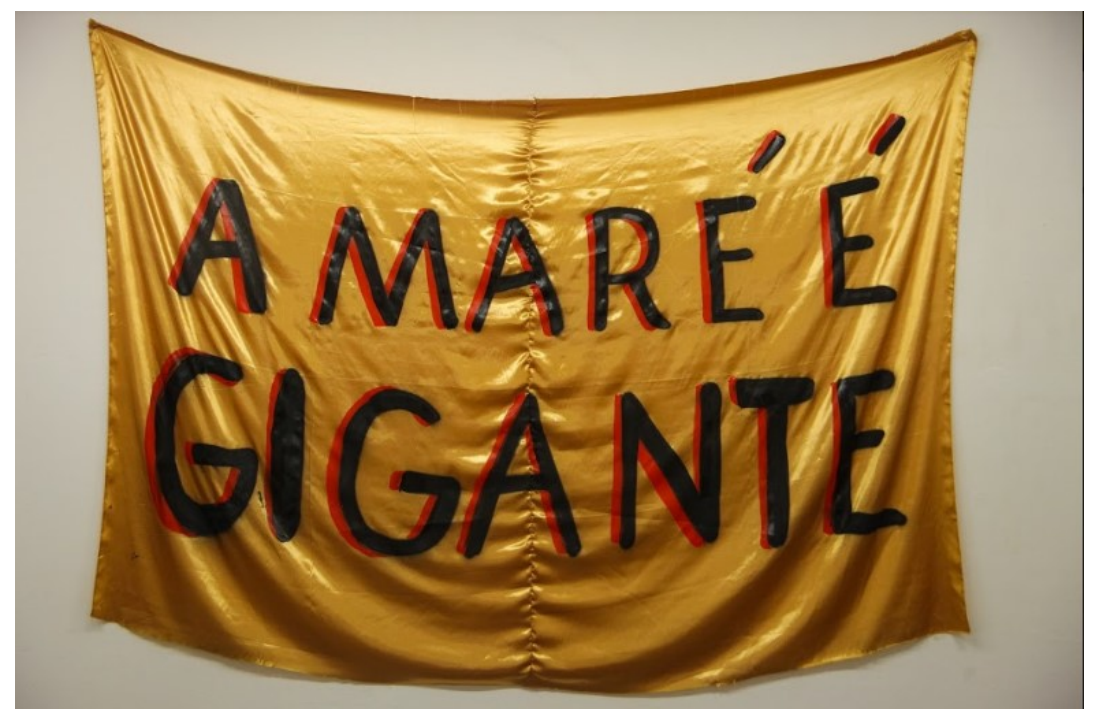

Fig. 1 - Mulambö, Gigante, 2019.

pintura sobre tecido, $300 \times 200 \mathrm{~cm}$

Isabela Souza da Silva; Jean Carlos de Souza dos Santos, Galpão Bela Maré: sentidos e práticas curatoriais... 


\section{Notas}

${ }^{1}$ A Maré é uma unidade territorial administrativa da cidade do Rio de Janeiro, que ocupa uma área de quase $4 \mathrm{~km}^{2}$ na região norte da cidade, rodeada pelas vias expressas Linha Amarela, Linha Vermelha e Avenida Brasil, configurando-se o maior conjunto de favelas da capital fluminense onde, segundo dados do Censo Maré, realizado entre 2012 e 2013, pela Redes da Maré em parceria com o Observatório de Favelas, vivem 139.073 pessoas. A Maré é um dos 160 bairros reconhecidos pela Prefeitura do Rio de Janeiro até 2010 e, dentro deste conjunto, é o nono bairro mais populoso da cidade do Rio de Janeiro, ocupando o $137^{\circ}$ lugar no que diz respeito ao IDS - Índice de Desenvolvimento Social.

${ }^{2}$ O Observatório de Favelas é uma organização da sociedade civil que atua há 18 anos nas áreas de pesquisa, consultoria e ação pública, dedicada à produção de conhecimento e de políticas públicas sobre favelas e fenômenos urbanos. Suas proposições e ações visam à construção de experiências que superem as desigualdades e fortaleçam a democracia a partir das favelas e periferias como territórios de potências e direitos dentro dos eixos Arte e Território, Políticas Urbanas, Direito à Vida e Segurança Pública, Comunicação e Educacão.O Relatório 2018 da organização está disponível em http: / / of.org.br/wp-content/uploads/2012/12/ RELATORIO-PROJETOS-OF_03.pdf. Redes sociais: Site I Facebook | Twitter | Instagram.

${ }^{3}$ www.automatica.art.br

${ }^{4}$ A ELÃ é um projeto experimental de formação artístico-pedagógica elaborada no Galpão Bela Maré, pelo Observatório de Favelas, a produtora Automatica e a Escola de Artes Visuais do Parque Lage. A proposta da ELÃ surgiu de um desejo de construção de um espaço de criação e de reflexões no campo estético e político; de fomento à produção artística contemporânea e se coloca como ambiente aberto a jovens artistas das regiões periféricas da metrópole do Rio de Janeiro. A primeira edição das atividades da ELÃ contou com o patrocínio da Amil, via lei do ISS, e as atividades formativas foram realizadas de agosto a novembro de 2019 , tendo como tema " $O$ nome que a gente dá às coisas" e contemplando 25 artistas e/ou representantes de coletivos artísticos, de origem periférica e espaços populares, com idade entre 18 e 35 anos, que se inscreveram via chamada pública. A chamada foi direcionada a artistas, em uma concepção ampliada do termo, de linguagens múltiplas, poéticas interdisciplinares e suportes diversos. Na seleção foram consideradas a diversidade de gênero, étnico racial, de sexualidade e território. Foram realizados 10 encontros formativos, com sete educadores/as e o acompanhamento integral da equipe educativa do Galpão Bela Maré e, ao final, em dezembro de 2019, montou-se a exposição Elã - $O$ nome que a gente dá às coisas com trabalhos inéditos resultantes do processo.

${ }^{5}$ Aqui estamos falando do livre acesso sem catracas e barreiras, da oferta de água gelada, do banheiro sempre limpo e disponível para uso, do mobiliário próconvívio disperso no espaço, dos livros disponíveis para consulta e de outros pequenos deleites da ordem do convite para presença sem pressa.

${ }^{6} \mathrm{O}$ principal corolário dessa representação pragmático, no que concerne ao campo da cultura, é se afirmar uma distincão entre as práticas artísticas, estrito senso, e as práticas culturais, lato senso, dos sujeitos das periferias. Assim, os discursos dominantes no campo da análise cultural da cidade consideram, em geral, que os sujeitos das periferias são expressivos na produção de experiências culturais que marcam sua identidade, mas não são capazes de produzir arte, pelo menos numa perspectiva profissional. Isso porque esses sujeitos não teriam capacidade conceitual para tal. Não por acaso, todas as formas de linguagem artística produzidas pelos grupos e sujeitos periféricos são adjetivadas de forma pejorativa: o teatro é "amador", a pintura é "naif"; a literatura é "marginal"; a música é "brega". (SILVA, 2015, p. 144)

${ }^{7}$ que possibilite uma espécie de arrancamento de discursos menores, aqueles que não descansam dentro de estruturas dominantes. 0 "menor" colocado pelos autores qualifica espécies de condicões revolucionárias no seio daquilo que está estabelecido, que, nesse caso, significaria "grande". A literatura menor, dita pelos autores acima trazidos, "está na situação exemplar de produzir enunciados novos" (DELEUZE; GUATTARI, 1977, p. 121), inéditos, outros, dissonantes. (SILVA, 2015, p. 12) 


\section{Referências}

BELA MARÉ. Portfólio Bela Maré. Disponível em encurtador.com.br/eszI3.

CARNEIRO, Sueli. A construção do outro como não-ser como fundamento do ser. Tese de doutorado. Universidade de São Paulo. São Paulo, 2005. 340 f.

DELEUZE, Gilles; GUATTARI, Félix. Kafka: por uma literatura menor. Belo Horizonte: Autêntica, 1977.

FANON, Frantz. Pele negra, máscaras brancas. Tradução de Renato da Silva. Salvador: EDUFBA, 2008.

GONZALEZ, Lélia. A categoria político-cultural de amefricanidade. Tempo Brasileiro, Rio de Janeiro, n. 92/93 (jan./jun.), p. 6982, 1988.

LAGNADO, Lisette. As tarefas do curador. Marcelina: revista do mestrado em artes visuais, FASM, São Paulo, v. 1, n. 1, 2008.

LIMA, Diane. Não me aguarde na retina. SUR - Revista Internacional de Direitos Humanos, São Paulo (Rede Universitária de Direitos Humanos), v. 15 , n. 28 , p. $245-$ 257, dez. 2018.

LIMA, Diane. Diálogos Ausentes e a Curadoria como Ferramenta de Invisibilização das Práticas Artísticas Contemporâneas AfroBrasileiras. Disponível em encurtador. com.br/uEGS3. Acesso em 9/1/2020.
PAULINO, Rosana. Diálogos Ausentes, Vozes Presentes. Disponível em encurtador.com.br/eilL6. Acesso em 9/1/2020.

REDES DA MARÉ. Censo Populacional da Maré. Rio de Janeiro: Redes da Maré, 2019.

RIBEIRO, Djamila. O Que É Lugar de Fala? Belo Horizonte: Letramento, 2017.

SILVA, Isabela Souza da. Observatório de Favelas e Galpão Bela Maré - reconhecendo e afirmando as potências dos territórios populares. In HERKENHOFF, Paulo. (Org). Rio XXI: Vertentes Contemporâneas. Rio de Janeiro: FGV, 2019, p. 144-155.

SILVA, Isabela Souza. e errar e deslizar e flanar sobre discursos-cidade de mulheres da MARÉ e. Dissertação (Mestrado em Planejamento Urbano e Regional). Instituto de Pesquisa e Planejamento Urbano e Regional, Universidade Federal do Rio de Janeiro, Rio de Janeiro, 2015. $123 \mathrm{f}$.

SILVA, Jailson de Souza. As práticas culturais das periferias mobilizando a cidade. In MASSER, Carlos Alberto; BRANCO, Carla. (Org). 40 vozes do Rio: avaliações e propostas culturais para uma cidade única. Rio de Janeiro: E-papers, 2015, p.142-146.

SILVA, Jailson de Souza. As Unidades de Polícia Pacificadora e os novos desafios para as favelas cariocas. Rio de Janeiro: Observatório de Favelas do Rio de Janeiro, 2010. Disponível em http://goo.gl/7xbXCX. Acesso em $20 / 11 / 2014$.

MARTINS, Leda Maria. Afrografias da Memória: O Reinado do Rosário do Jatobá. São Paulo: Perspectiva, 1997. 